\title{
Mapping out the research field of adult education and learning
}

Lifelong Learning Book Series Volume 24 by Andreas Fejes and Erik

Nylander, Switzerland, Springer Nature, 2019, 234 pp., €59 (hardback) 93, ISBN 978-3-030-10945-5

\section{Camilla Fitzsimons}

To cite this article: Camilla Fitzsimons (2019): Mapping out the research field of adult education and learning, Studies in the Education of Adults, DOI: 10.1080/02660830.2019.1694768

To link to this article: https://doi.org/10.1080/02660830.2019.1694768

曲 Published online: 25 Nov 2019.

Submit your article to this journal $\longleftarrow$

Џ Article views: 23

Q View related articles $\sqsubset$

View Crossmark data $₫$ 
Mapping out the research field of adult education and learning. Lifelong Learning Book Series Volume 24, edited by Andreas Fejes and Erik Nylander, Switzerland, Springer Nature, 2019, 234 pp., €59 (hardback) 93, ISBN 978-3-03010945-5

This book is presented in four parts - (1) historicising the research field; (2) biometrics on international performance; (3) trends in research modality; and (4) debates on comparative research. A short conclusion summarises and elaborates main findings. Its key strength, is its capacity to critique itself as the book continually exposes the limitations of academic research including the gatekeeper role played by editors. In my own attempt to bring this to the fore, word-count impacts my capacity to offer a more thorough assessment. Instead I begin with a chapter-by-chapter summary before lingering on four interconnected shortcomings; each of which are explicitly named within the publication itself.

Part 1 begins with the editor's synopsis of a linguistically anglicised research field which encompasses competing visions of $\mathrm{AE}$ but remains shadowed by a policy-influenced individualist orientation. Rubenson and Elfert (Ch. 2) then describe this arena in more detail, pessimistically depicting a 'weak field' given its interwoven characteristics, tendency to fracture into sub-disciplines and absence of agreed standards. I thank Zeuner (Ch. 3) for successfully turning my gaze away from research publications in isolation, and towards the aims of AE. I learned how, historically, German research inquired into participant experiences so as to inform practice; an interdependence Zeuner perceives as less evident contemporarily.

Across three discrete chapters, part 2 offers biometric determinations of citation patterns (Ch. 4), prevailing authors (Ch. 5) and dominant countries (Ch. 6). Collectively these reveal the invisible forces that shape the field. They capture Anglo-centrism with minimal collaboration across continents and a male-centric pecking order of citations (p. 83) despite more female contributors overall. As a woman, I was struck by the researchers' assertion that men have to do much less to 'become a name' in the research arena (p. 84). Part 2 also uncovers a hierarchy of journal status maintained through the powerful databases Web of Science and Scopus. Given its overlapping authorship, I wondered if greater collaboration might have collapsed some commonalities including North-European and US dominance, the limitations of biometrics (including researcher choices) and the subjectivity of editors.

Part 3 illuminates and at times problematises the ubiquity of qualitative approaches (Ch. $7,9)$ whilst Boeren (Ch. 8) rallies her quantitative-oriented allies to plug a perceived knowledge-gap caused by an underrepresentation of quantitative studies. She encourages others to appreciate existing data-sets such as the often cited International Adult Literacy Survey (IALS).

Finally, part 4 offers energetic debate about comparative research as Field et al. (Ch. 10) provocatively suggest the end of International Comparative Research, in part because of a diminishing notion of the nation-state; qualitative dominance; and ongoing fragmentation, deinstitutionalisation and diversification. Centrally they problematise the purpose of comparative studies and are defiant in response to Milana's counter-arguments towards a newly coined Global and Comparative Research (Ch. 11). Whilst Milana usefully captures conditions needed for comparative studies, illuminates researcher subjectivity and identifies 
methodological challenges, she is less convincing about the rationale for comparatives and, for me, underplays policy-maker subjectivity.

Overall, this is a worthwhile, informative read. The first of four interrelated features that stay with me is the importance of remembering this is not a book about AE, but a book about a Bourdieusian conceived 'research field' that describes the individuals, groups and institutions who, perhaps sometimes unwittingly, seek to maximise their position within AE (Ch. 2, 4, 9, 13). Although not always explicit, many contributors allude to controversies amidst this largely privatised publishing industry that crudely benchmarks both the importance of a particular discipline, and the status of individuals within that discipline. Those selected for publication construct a space where they 'battle over [a] truth in which we, as researchers are engaged in' (p. 158). Few would refute the partiality of this 'truth', indeed the historical contexts sometimes offered, have little resonance outside of the dominant terrains. This situational truth is thus highly subjective and often inaccessible, both financially and culturally, to those who access AE; the very people upon which us academics ply our trade. The echo-chamber this creates has huge sway in terms of individualised promotion and remuneration and, in turn, can influence who gets the research grants. Moreover, as academics move closer to so-called research-scholarship and away from teaching-practice (p. 18) they are frequently replaced by precariously employed practitioners often excluded from academic prestige.

A second self-contained appraisal, although not held throughout, is a sense of epistemological congruence between the practice of $\mathrm{AE}$, and qualitative research. As a practice that is experiential at its core, it makes sense to me that interpretivist, narratively oriented, constructivist ontologies should shape our field and although this book both showcases (Ch. 4-6) and promotes (Ch. 8, 11) quantitative research, it is important to maintain how many aspects of our work are quite simply immeasurable. Should we not therefore resist pressures from supranational organisations such as the EC who seek 'evidence' about what works, and exert significant power in shaping the field by setting parameters around research grants (p. 17).

Thirdly, and repeatedly emphasised by the authors, it is worth re-stating limitations to any study that draws inferences from such narrowly defined data. Many chapters base their findings on between 3 and 5 self-selected journals thus confirming, and contributing to, the prestige of Adult Education Quarterly, International Journal of Lifelong Education, Studies in Continuing Education, and the more vocationally oriented Journal of Education and Work, and Journal of Workplace Learning. Moreover, the inclusion of these latter publications undoubtedly contribute to the prevalence of the sociocultural perspectives measured (p. 68) and the near-absence of a focus on teaching-practice (p. 23).

My final, and most central observation is again self-disclosed (Ch. 13) when the editors re-emphasise the West-Centric nature of the field. I could not help wondering though, if a better way of countering this short-fall might be to showcase an alternative by inviting contributions from outside the dominant zones. In fact, Käpplinger (Ch. 9) confirms how, when we create the conditions for participation, those currently excluded are keen to get involved. If English is the limitation, what about former British colonies where this barrier does not exist or why not improve translation services? Somewhat as an aside, but related given my focus on language, it would be remiss not to highlight one error (p. 65) where readers are incorrectly told Freire's original contributions were in Spanish (and not Portuguese). This is unfortunate given the book's call to democratise language, indeed other grammatical errors add to its architecture by interrupting the reader's flow in a way that reminded me how some contributors are forced to publish in a secondary language. 
In true $\mathrm{AE}$ fashion, this book left me with questions rather than answers. Most of all, it encouraged me to reflexively engage with my own researcher identity. As I turned the mirror on myself, I contemplated the purpose of research in the face of rising intersectional inequality, homelessness and mass-migration, and climate catastrophe. Surely it cannot just be about academic ambition or often distracting attempts to influence neoliberalist policy-makers. I for one quite like being out of step with the plethora of individualist, managerialist policies I am often bound by as I contemplate my own contribution in these turbulent times.

\section{ORCID}

Camilla Fitzsimons (D) http://orcid.org/0000-0001-5686-9993

Camilla Fitzsimons Department of Adult and Community Education, Maynooth University, Kildare, Ireland

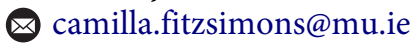

(C) 2019 Camilla Fitzsimons https://doi.org/10.1080/02660830.2019.1694768 